\title{
Sexual abstinence and restraint in Man allow a harmonic wound healing, owing to blood cortisol increment
}

\author{
Piotr Brzezinski, Lorenzo Martini
}

University of Siena, Department of Pharmaceutical Biotechnologies, Via A. Moro 2, 53100 Siena, Italy

Corresponding author: Prof. Lorenzo Martini, M.Sc., E-mail: martini36@unisi.it

\begin{abstract}
Aims of our investigation is to demonstrate that $M$ an who suffers from sexual abstinence or restraint (because of medical, psychological, legal, social, financial, philosophical, moral, or religious reasons.) shows an excellent wound healing after burns or skin lacerations, and this is due to the fact that $\mathrm{M}$ an's blood cortisol increases when is expecting or living a physical or mental stress. We have recruited different volunteers, who cannot have sexual intercourses or outercourses at all and have some wounds or burns on their body and we compare the rapidity of their wound repair to the wound healing process of individuals who lead a normal sexual life and use or not wound healing agents (as Neosporin). Among these individuals, we have selected even a haemophyliac and the results are quite pregnant and evocative. The physiological process of scarring is more slow in M en who refrain from sex, even the physiological phenomenon is more harmonic and aesthetically more satisfactory.
\end{abstract}

Key words Sexual restraint; Sexual abstinence; Wound healing; Neosporin; C utometer

\section{INTRODUCTION}

W right in 1985 referred that individuals in passionate love often experience a strong desire to engage in sexual intercourse with their partners [1]. In a previous study (C rockett, W right, \& Loving) individuals who were engaging in less sexual intercourse during the early stages of their romantic relationship were more likely to experience acute elevations in cortisol in response to a passionate love prime. The $A$. examined whether sexual frustration mediates any association between sexual frequency and cortisol. Subjects underwent the same passionate love prime employed in Crockett et al.'s study, and completed measures of sexual intercourse frequency and feelings of sexual frustration. The A. collected salivary cortisol samples before and after the prime. Sexual frequency was significantly correlated with sexual frustration, such that individuals who were engaging in less sex experienced more sexual frustration, and consequently they showed a strong level of serum/ saliva cortisol content.

Asfrustration is a sort of psychological stress anyway, we focused our attention on the study of other AA [2] who used a within-subjects design to examine healthy adult participants' ( $n=20$ men, $n=20$ women) subjective stress and salivary cortisol responses to the standard TSST (involving public speaking and math) and the newly created I owa Singing Social Stress Test (I-SSST). The I-SSST is similar to the TSST, but with a new twist: public singing. Results indicated that men and women reported similarly high levels of subjectivestress in response to both tasks. However, men and women demonstrated different cortisol responses: men showed a robust response to both tasks, and women displayed a smaller response.

So, it is fully irrefutable that $M$ an manifests always a greater increase of cortisol in serum and/or saliva, before

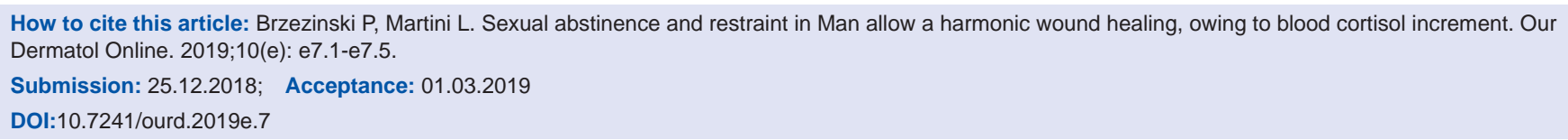


or after a psychological stress of whichever type.

To confirm all these hypothesis, there are many other testimonies that assert that $M$ an produces more cortisol than Female, only expecting the stress that shall abruptly occur.

Someresearchersinvestigated in four independent studies, sex differences in cortisol responses to psychological stress in healthy adolescents and adults (total $n=153$ ). Public speaking and mental arithmetic in front of an audience (Studies 1-3) reliably induced increases in free cortisol levels in both sexes with 2- to 4-fold increases above baselinelevels. M ean cortisol responses were 1.5- to 2-fold higher in men compared with women. In Study 3, cortisol profiles were additionally investigated after human corticotropin-releasing hormone (h-CRH) and bicycle ergometry until exhaustion. Here, both sexes showed very similar adrenocortical responses. Furthermore, men showed elevated cortisol levels in anticipation of the psychological stress situation without actually having to perform the tasks.

This is an extremely interesting finding, as cortisol and the stress response have known deleterious effects on the immune system. High levels of perceived stress and increases in cortisol have been found to lengthen wound-healing time in healthy, male adults. Those who had the lowest levels of cortisol the day following a $4 \mathrm{~mm}$ punch biopsy had the fastest healing time [3].

In dental students, wounds from punch biopsies took an average of $40 \%$ longer to heal when performed three days before an examination as opposed to biopsies performed on the same students during summer vacation [4]. This is in line with previous animal studies that show similar detrimental effects on wound healing, notably the primary reports showing that turtles recoil from cortisol $[5,6]$.

Now it is well established that high levels of cortisol lengthen always wound healing, even though some other A.A. [ 7] examined skin thickness, water content and collagen content in epidermal areas adjacent to the wounds of individuals presenting a drastic increase of cortisol after stress or expecting a source of physical or psychological stress.

C ortisol treatment resulted in reduced extensibility but increased stiffness for ten day wounds and increased collagen content of the skin distant to the wound.
In conclusion, psychological stress and anticipation and/or expectation of a source of stress, does increase considerably cortisol levels in serum and saliva in $\mathrm{M}$ an and this phenomenon induces a harmonic wound healing, even if more long lasting and durable.

\section{MATERIALS AND METHODS}

W e have selected 7 volunteers (males $26-47 \mathrm{y}$. old) and these are represented by the following groups:

4 of them $(a, b, c, d)$ were bricklayers who are forced to live and work far from their wives or fiancées, moreover they presented always a lot of wounds on their body, because of their hard job.

2 (e and f) of them were felons, idest convicts in a governmental jail, who have low chances to encounter women for sexual intercourses 1 of them (g) was a haemophiliac who has had prior a great car crash and presented an avalanche of scares and wounds and, for this fact, he was forced to stay at home with no chance of experiencing sexual intercourses during the convalescence.

We have recruited even 5 volunteers ( $h, I, I, m$ and $n$ ) who worked in the steel sector and presented similar wounds to all the other volunteers (light burns, wounds provoked by sharp tools and scratches and who have regular sex) and we prayed them to spread onto the skin injuries Neosporin (bacitracin/neomycin/polymyxin B ointment).

The Authors of this short communication, who have instead regular sex intercourses, used to inflict on themselves, on purpose, the same types of wounds and scares presented by all the other subjects and used to number all the days necessary for the complete wound healing and remission, to compare with the results of the other volunteers and they represent Case 0 and $p$.

It must be stressed that light burns forecast 18-20 days to a complete recuperation, wounds provoked by sharp tools need 10 days of cure and scratches seven days.

In order to evaluate the progress of the different wound healing we have used a $\mathrm{C}$ utometer, apt to measure the collagen content in the volunteers' dermis owing to the method of suption.

The C utometer (C utometer dual M PA 580 by C ourage + Khazaka electric G mbh,Koeln,Germany) is destined 
to measure elasticity of the upper skin layer using negative pressure which deforms the skin mechanically. The measuring principle is based on the suction method. Negative pressure is created in the device and the skin is drawn into the aperture of the probe and after a defined time released again. Inside the probe, the penetration depth is determined by a non-contact optical measuring system. Thisoptical measuring system consists of a light source and a light receptor, as well as two prisms facing each other, which project the light from transmitter to receptor. The light intensity varies due to the penetration depth of the skin. The resistance of the skin to the negative pressure (firmness) and its ability to return into its original position (elasticity) are displayed as curves (penetration depth in $\mathrm{mm} /$ time) in real time during the measurement. This measurement principle allows getting information about the elastic and mechanical properties of skin surface and enables to objectively quantify skin aging.

From these curves interesting measurement parameters can be calculated, by mean of all the parameters that are useful to calculate the different values and to obtain the final result.

Parameters encompass three different types of mechanical demenaours:

Type $\mathrm{R}$, that include:

R0: This parameter represents the passive behaviour of the skin to force.

$\mathrm{R} 1$ : represents the ability of the skin to return to its original state.

R2 stands for the gross elasticity, the closer the value is to $1(100 \%)$ the more elastic the curve and is a very important parameter.

R3 is the last curve, compared to the maximum amplitude of the first curve. "Tiring effects" of the skin are visible, as the amplitude increases with each new suction.

R4 represents the last minimum amplitude compared to the first curve, "tiring effects" of the skin are visible, as the ability of redeformation decreases with each new suction.

$\mathrm{R} 5$ is not but the net elasticity, the closer the value is to 1 ( $100 \%)$ the more elastic the skin. at all, the closer the value to 0 the more elastic the material.
R6 is the portion of the visco-elasticity on the elastic part of the curve. The smaller the value the higher the elasticity.

R7 stands for the portion of the elasticity compared to the complete curve, the closer the value is to 1 (100\%) the more elastic the skin.

$\mathrm{R} 8$ is the closer $\mathrm{U}$ a of the first curve is to 0 the greater the ability of the skin to return into its original state.

R9 represents tiring effects of the skin after repeated sucking in of the skin. The smaller R9 the smaller the tiring effects.

Type F that include:

F 2 that is the area above the upper envelope-curve.

F 3 that stands for the area within the envelope curves.

$\mathrm{F} 4$ that represents the skin firmness: and the smaller $\mathrm{F} 4$ the more the skin resists to the suction ( skin firmness).

We availed, for the total measure of the skin elasticity, of R2 parameter, that indicates the elevation rate of the skin $(\mathrm{E} / \mathrm{mm})$ as a function of time (s).

R2 is correlated strictly with the collagen content and the scale can be identified as a simplest scale from 0 to 1 ( 0 indicates a dermis completely devoid of collagen and 1 represents a dermis with a rich content of collagen).

As far as the other parameters are concerned, we have observed that generally higher values of R4, R9 and $F 2$ and lower values of $F 3$ are typical of dermis almost devoid of collagen.

F 3 values were not significantly altered, during the processes of wound healing, in almost all the cases [8].

Table 1: The measures of $\mathrm{R} 2$ of volunteers during their natural wound healing process, in case of first degree burns (days: $3^{\text {rd }}$, $\left.7^{\text {th }}, 14^{\text {th }}, 20^{\text {th }}\right)$

\begin{tabular}{lcccc}
\hline Case & $\mathbf{R 2}$ at $\mathbf{3}^{\text {rd }}$ day & $\mathbf{R} 2$ at $\mathbf{7}^{\text {th }}$ day & $\mathbf{R} 2$ at $\mathbf{1 4}^{\text {th }}$ day & $\mathbf{R} 2$ at $\mathbf{2 0}^{\text {th }}$ day \\
\hline A & 0.2 & 0.4 & 0.7 & 0.9 \\
B & 0.1 & 0.3 & 0.6 & 1.0 \\
C & 0.2 & 0.5 & 0.7 & 0.8 \\
D & 0.1 & 0.4 & 0.6 & 0.9 \\
E & 0.3 & 0.6 & 0.8 & 1.0 \\
F & 0.4 & 0.7 & 0.9 & 1.0 \\
G & 0.1 & 0.2 & 0.3 & 0.7 \\
\hline
\end{tabular}


Table 2: The values of $\mathrm{R} 2$ of volunteers during their natural wound healing process, in case of wounds or scares provoked by sharp tools (days: $3^{\text {rd }}, 5^{\text {th }}$ and $10^{\text {th }}$ )

\begin{tabular}{lccc} 
Case & R2 at $^{\text {rd }}$ day & $\mathbf{R 2}^{\text {at }} \mathbf{5}^{\text {th }}$ day & R2 at $\mathbf{1 0}^{\text {th }}$ day \\
\hline A & 0.3 & 0.4 & 0.8 \\
B & 0.2 & 0.2 & 0.7 \\
C & 0.1 & 0.3 & 0.9 \\
D & 0.2 & 0.4 & 1.0 \\
E & 0.3 & 0.5 & 0.9 \\
F & 0.1 & 0.6 & 0.9 \\
G & 0.1 & 0.2 & 0.6 \\
\hline
\end{tabular}

Table 3: The values of R2 of volunteers during their natural wound healing process, in case of normal scratches (days: $2^{\text {nd }}, 4^{\text {th }}$ and $7^{\text {th }}$ )

\begin{tabular}{lccc}
\hline Case & R2 $^{\text {at } \mathbf{2}^{\text {nd }} \text { day }}$ & $\mathbf{R 2}$ at $\mathbf{4}^{\text {th }}$ day & R2 at $^{\mathbf{7}^{\text {th }}}$ day \\
\hline A & 0.3 & 0.5 & 1.0 \\
B & 0.4 & 0.6 & 1.0 \\
C & 0.2 & 0.4 & 0.8 \\
D & 0.3 & 0.6 & 1.0 \\
E & 0.4 & 0.7 & 0.9 \\
F & 0.3 & 0.6 & 1.0 \\
G & 0.1 & 0.3 & 0.6 \\
\hline
\end{tabular}

Table 4: The values of R2 of volunteers during their wound healing process using Neosporin, in case of first degree burns (days: $3^{\text {rd }}, 7^{\text {th }}, 14^{\text {th }}, 20^{\text {th }}$ )

\begin{tabular}{lcccc}
\hline Case & $\mathbf{R} 2$ at $^{\text {rd }}$ day & $\mathbf{R} \mathbf{2}$ at $\mathbf{7}^{\text {th }}$ day & $\mathbf{R} 2$ at $\mathbf{1 4}^{\text {th }}$ day & $\mathbf{R} \mathbf{2}$ at $\mathbf{2 0}^{\text {th }}$ day \\
\hline H & 0.1 & 0.2 & 0.4 & 0.4 \\
I & 0.2 & 0.3 & 0.3 & 0.6 \\
L & 0.1 & 0.2 & 0.3 & 0.5 \\
M & 0.2 & 0.4 & 0.4 & 0.6 \\
N & 0.1 & 0.1 & 0.3 & 0.4 \\
\hline
\end{tabular}

Table 5: The values of R2 of volunteers during their wound healing process using neosporin, in case of wounds or scares provoked by sharp tools (days: $3^{\text {rd }}, 5^{\text {th }}$ and $10^{\text {th }}$ )

\begin{tabular}{lccc}
\hline Case & R2 at $\mathbf{3}^{\text {rd }}$ day & R2 at $^{\text {th }}$ day & R2 at $\mathbf{1 0}^{\text {th }}$ day \\
\hline $\mathrm{H}$ & 0.2 & 0.2 & 0.6 \\
$\mathrm{I}$ & 0.1 & 0.4 & 0.7 \\
$\mathrm{~L}$ & 0.3 & 0.3 & 0.8 \\
$\mathrm{M}$ & 0.2 & 0.2 & 0.7 \\
$\mathrm{~N}$ & 0.4 & 0.5 & 0.6 \\
\hline
\end{tabular}

\section{RESULTS}

In Table 1 the measures of $\mathrm{R} 2$ of the seven volunteers (the ones who are forced to sexual absence or restraint of sexual intercourses) during their natural wound healing process, in case of first degree burns. M easures were taken at different days $\left(3^{\text {rd }}, 7^{\text {th }}, 14^{\text {th }}, 20^{\text {th }}\right)$.

In table 2 all the values of $\mathrm{R} 2$ of the same 7 volunteers during their natural wound healing process, in case of wounds or scares provoked by sharp tools. M easures were taken at different days $\left(3^{\text {rd }}, 5^{\text {th }}\right.$ and $\left.10^{\text {th }}\right)$.

In Table 3 all the values of R2 of the same 7 volunteers during their natural wound healing process, in case of

(c) Our Dermatol Online e.2019
Table 6: The values of R2 of volunteers during their wound healing process, using Neosporin, in case of normal scratches (days: $2^{\text {nd }}, 4^{\text {th }}$ and $7^{\text {th }}$ )

\begin{tabular}{lccc}
\hline Case & R2 at $^{\mathbf{2}^{\text {nd }}}$ day & $\mathbf{R 2}$ at $^{\text {th }}$ day & R2 at $\mathbf{7}^{\text {th }}$ day \\
\hline $\mathrm{H}$ & 0.3 & 0.5 & 0.7 \\
$\mathrm{I}$ & 0.2 & 0.4 & 0.6 \\
$\mathrm{~L}$ & 0.1 & 0.4 & 0.7 \\
$\mathrm{M}$ & 0.2 & 0.2 & 0.6 \\
$\mathrm{~N}$ & 0.3 & 0.3 & 0.5 \\
\hline
\end{tabular}

Table 7: The measures of R2 of the A.A. during their natural wound healing process, in case of first degree burns (days: $3^{\text {rd }}, 7^{\text {th }}, 14^{\text {th }}, 20^{\text {th }}$ )

\begin{tabular}{lcccc}
\hline Case & $\mathbf{R} 2$ at $^{3^{\text {rd }}}$ day & $\mathbf{R} \mathbf{2}$ at $^{\mathbf{7}^{\text {th }}}$ day & $\mathbf{R} \mathbf{2}$ at $\mathbf{1 4}^{\text {th }}$ day & $\mathbf{R} \mathbf{2}$ at $\mathbf{2 0}^{\text {th }}$ day \\
\hline $\mathrm{O}$ & 0.2 & 0.3 & 0.4 & 0.8 \\
$\mathrm{P}$ & 0.1 & 0.2 & 0.3 & 0.7 \\
\hline
\end{tabular}

Table 8: The values of R2 of the AA during their natural wound healing process, in case of wounds or scares provoked by sharp tools (days: $3^{\text {rd }}, 5^{\text {th }}$ and $10^{\text {th }}$ )

\begin{tabular}{lccc}
\hline Case & $\mathbf{R} 2$ at $^{\mathbf{3}^{\text {rd }}}$ day & $\mathbf{R 2}$ at $\mathbf{5}^{\text {th }}$ day & $\mathbf{R} \mathbf{2}$ at $\mathbf{1 0}^{\text {th }}$ day \\
\hline $\mathrm{O}$ & 0.2 & 0.4 & 0.6 \\
$\mathrm{P}$ & 0.1 & 0.3 & 0.6 \\
\hline
\end{tabular}

Table 9: The values of $R 2$ of the AA during their natural wound healing process, in case of normal scratches (days: $2^{\text {nd }}, 4^{\text {th }}$ and $7^{\text {th }}$ )

\begin{tabular}{lccc}
\hline Case & $\mathbf{R} 2$ at $^{\mathbf{2}^{\text {nd }}}$ day & $\mathbf{R 2}$ at $\mathbf{4}^{\text {th }}$ day & $\mathbf{R} \mathbf{2}$ at $\mathbf{7}^{\text {th }}$ day \\
\hline $\mathrm{O}$ & 0.2 & 0.2 & 0.8 \\
$\mathrm{P}$ & 0.1 & 0.2 & 0.6 \\
\hline
\end{tabular}

normal scratches. M easures were taken at different days $\left(2^{\text {nd }}, 4^{\text {th }}\right.$ and $\left.7^{\text {th }}\right)$.

In table 4 all the values of $\mathrm{R} 2$ of the five volunteers (who can assert to have a good sex achievement)

during their wound healing process using Neosporin, in case of first degree burns. M easures were taken at different days $\left(3^{\text {rd }}, 7^{\text {th }}, 14^{\text {th }}, 20^{\text {th }}\right)$.

In Table 5 all the values of R 2 of the same 5 volunteers during their wound healing process using neosporin, in case of wounds or scares provoked by sharp tools. $M$ easures were taken at different days $\left(3^{\text {rd }}, 5^{\text {th }}\right.$ and $\left.10^{\text {th }}\right)$.

In Table 6 all the values of R2 of the same 5 volunteers during their wound healing process, using N eosporin, in case of normal scratches. Measures were taken at different days $\left(2^{\text {nd }}, 4^{\text {th }}\right.$ and $\left.7^{\text {th }}\right)$.

In Table 7 the measures of R2 of the A.A. (who can assert to have a regular sexual lifestyle) during their natural wound healing process, in case of first degree burns. $M$ easures were taken at different days $\left(3^{\text {rd }}, 7^{\text {th }}, 14^{\text {th }}, 20^{\text {th }}\right)$.

In Table 8 all the values of $\mathrm{R} 2$ of the AA during their natural wound healing process, in case of wounds or 
scares provoked by sharp tools. M easures were taken at different days ( $3^{\text {rd }}, 5^{\text {th }}$ and $\left.10^{\text {th }}\right)$.

In Table 9 all the values of R2 of the AA during their natural wound healing process, in case of normal scratches. M easures were taken at different days $\left(2^{\text {nd }}, 4^{\text {th }}\right.$ and $\left.7^{\text {th }}\right)$.

We desire to recall Case $O$ (the corresponding $A$ ) is younger than $C$ ase $P$, for this fact, the first measurements of the elasticity (= collagen content) is higher in the younger subject, than in the other $\mathrm{A}$.

\section{CONCLUSIONS}

We have noticed, with a great pleasure, that as we had hypothesized, men who presented a higher cortisol level because of sexual abstinence or restraint, may benefit of a wound healing physiological process less fast than men who have a regular sex lifestyle, even if the scarring ismore harmonic and collagen content in dermal layer is very high.

Actually we have collected only three results of cortisol blood samples: one of the first group of volunteers, another of the second group and one of an Author of this paper.

Another suggestive discovery is that Case $g$, the haemophiliac, shows always, in whichever type of wound or burn, lowest values of R2.

His collagen content is extremely poor in all the steps of his gradual wound healing.

And this was affirmed previously by some researchers [9] who had studied the optimization of the process of scarring in haemophilia.

\section{Statement of Human and Animal Rights}

All procedures followed were in accordance with the ethical standards of the responsible committee on human experimentation (institutional and national) and with the Helsinki Declaration of 1975, as revised in 2008.

\section{Statement of Informed Consent}

Informed consent was obtained from all patients for being included in the study.

\section{REFERENCES}

1. Writght BL. The downside of sexual restraint: sexual frequency, frustration, and stress; Thesis presented to the Faculty of the Graduate School of The University of Texas at Austin, May 2012.

2. Reschke-Hernández AE, O kerstrom KL, Edwards AB, Trane D. Sex and stress: Men and women show different cortisol responses to psychological stress induced by the Trier Social Stress Test and the Iowa Singing Social Stress Test. J Neurosci Res. 2017;95:106-14.

3. Ebrecht M, Hextall J, Kirtley LG, Taylor A, Dyson M, Weinman J. Perceived stress and cortisol levels predict speed of wound healing in healthy male adults. Psychoneuroendocrinol. 2014;29:798-809.

4. Marucha PT, Kiecolt-Glaser JK, Favagehi M. Mucosal wound healing is impaired by examination stress. Psychosom Med. 1988;60:362-5.

5. Zhou X, Xie M, Niu C, Sun R. The effects of dietary vitamin C on growth, liver vitamin $\mathrm{C}$ and serum cortisol in stressed and unstressed juvenile soft-shelled turtles (Pelodiscus sinensis). Comparative Biochemistry and Physiology. Part A, Molecular \& Integrative Physiology. 2003.

6. Kirschbaum C, Wüst S, Hellhammer D. Consistent sex differences in cortisol responses to psychological stress. Psychosom Med. 1992;54:648-57.

7. Oxlund H, Fogdestam I, Viidik A. The influence of cortisol on wound healing of the skin and distant connective tissue response. Surg Gynecol O bstet. 1979;148:876-80.

8. D obrev H. Application of Cutometer area parameters for the study of human skin fatigue. Skin Res Technol. 2005;11:120-2.

9. Hoffman M, Monroe D M. Wound healing in haemophilia--breaking the vicious cycle. Haemophilia. 2010;16 Suppl 3:13-8.

Copyright by Piotr Brzezinski, et al. This is an open access article distributed under the terms of the Creative Commons Attribution License, which permits unrestricted use, distribution, and reproduction in any medium, provided the original author and source are credited.

Source of Support: Nil, Conflict of Interest: None declared. 